\title{
Who adopts MIND/FIND in INTERPOL's fight against international crime and terrorism?
}

\author{
Walter Enders \\ Department of Economics and Finance \\ University of Alabama \\ wenders@cba.ua.edu \\ Todd Sandler \\ School of Economic, Political \& Policy Sciences \\ University of Texas at Dallas \\ tsandler@utdallas.edu
}

June 2011

\begin{abstract}
This article determines the key factors inducing INTERPOL countries to institute MIND/FIND, a technology which facilitates systematic searches of people, motor vehicles, and documents at international transit points. This integrated solution assists countries in curbing international crime and terrorism. Based on discrete-choice models, the analysis identifies income per capita, population, democratic freedoms, and anticipated searches for suspects as the key determinants of whether INTERPOL countries install MIND/FIND. Ethnic diversity, international arrivals, cost proxies, and arrests prior to adoption are not important considerations in decisions to install MIND/FIND. External financial support is an essential factor identifying likely non-adopters who installed MIND/FIND.
\end{abstract}

Keywords: INTERPOL, MIND/FIND, logit and probit, international terrorism, international crime

JEL codes: D74, H41, K42 


\section{Who adopts MIND/FIND in INTERPOL's fight against international crime and terrorism?}

\section{Introduction}

In the last half of the twentieth century, globalization led to ever greater cross-border flows including trade, investment, resources, information, pollution, diseases, crime, terrorism, and political instability. The increase in the flow of transnational externalities raises collective action concerns as nations must work together to ameliorate inefficiencies stemming from independent national actions. These inefficiencies are especially germane to the control of transnational terrorism as nations resist losses in autonomy over security matters (Sandler 2005). Similar autonomy worries are tied to curbing transnational crime, for which international cooperation can bolster arrests.

In recent years, the world community has had to address the adverse consequences from greater international flows of criminals and terrorists. Transnational crime involves the Russian mafia, drug cartels, counterfeit rings, human trafficking, corruption, and high-technology activities. Transnational terrorism concerns groups such as al-Qaida, Jemaah Islamiyah, Lashkar-e-Taiba, Islamic Jihad, Hezbollah, Mujahedin-e-Khalq, and others. The prevalence of transnational criminals and terrorists means that countries may profit from collectively utilizing technological linkages provided by international organizations to apprehend these agents. The International Criminal Police Organization (INTERPOL) is uniquely positioned to allow countries worldwide to share information and to coordinate actions against international criminals and terrorists. Such linkages yield network externalities whose benefits increase with the number of linked nations. In a recent article, Sandler et al. (2011) showed that INTERPOL returned a huge payback to member countries that used its communication linkages to arrest suspected terrorists. Based on 12 counterfactual scenarios, these authors estimated that each 
dollar spent on INTERPOL counterterrorism arrest efforts returned $\$ 200$ on average. This rather large return is consistent with a network externality that has not yet been fully internalized.

The efficacy of INTERPOL-assisted coordination is fostered if member countries connect to the Mobile INTERPOL Network Database (MIND) or the Fixed INTERPOL Network Database (FIND). MIND/FIND offers integrated solutions for linked countries to check people, motor vehicles, and travel documents with speed and accuracy against INTERPOL's global databases. Checking people, for example, also facilitates arrests of suspected terrorists or criminals, who have been flagged by or whose apprehension has been requested by either INTERPOL or one of its member countries. With MIND/FIND, national law enforcement authorities have the capacity to perform systematic and thorough searches of all passports, vehicles, or persons at any particular place, and especially at border crossings on land and other points of international entry (seaports, and airports).

The primary purpose of this article is to determine the key factors behind why some countries adopted MIND/FIND and others did not. Currently, 53 of 188 member countries of INTERPOL use MIND, FIND, or both. Given that the implementation of MIND/FIND is relatively inexpensive, the puzzle is why only $28 \%$ of INTERPOL's members have installed this technology. To ascertain the determinants of MIND/FIND adoption, we estimate alternative discrete-choice models - i.e., probit, logit, and extreme value distributions - that provide a consistent set of baseline regressions. An impure public good model serves as the theoretical underpinning of the adoption decision, where countries are motivated by country-specific and global public benefits, derived from better border surveillance. A secondary purpose is to identify the countries that share the same general characteristics as those of the adopters, but did not institute MIND/FIND. A tertiary purpose is to recommend some policies that could enhance the adoption of MIND/FIND. For example, subsidization from external sources expand the 
implementation of MIND/FIND. For African countries, this subvention was supported by Germany from February 2008 to June 2011 (INTERPOL 2009 and private communication with INTERPOL's General Secretariat). A more broadly based support system is needed that is coordinated by INTERPOL to shore up particularly important border crossings favored by criminals and terrorists.

The main finding is that a country's income per capita, population, and democratic freedoms are the key determinants of which countries institute MIND/FIND. When we dichotomize the member countries into those that are rich and poor, income per capita and freedoms are the key considerations for poor countries to institute MIND/FIND. For the sample countries, international arrivals, pre-adoption arrests, a MIND/FIND cost proxy, ethnic diversity, and per capita member contributions to INTERPOL are not significant determinants of the adoption of MIND/FIND. Searches per capita in the Nominal database are also a significant indicator of MIND/FIND adoption. The Nominal database indicates, among other things, suspected criminals and terrorists. To address an obvious endogeneity problem associated with searches, we instrument that variable based on the rule of law, which measures how closely citizens abide by society's legal framework (Kaufmann et al. 2008). Societies that rank high on the rule of law have less crime and violence as laws are rigorously enforced and criminals are incarcerated. We also instrument searches per capita with a corruption index and political and civil liberties.

The remainder of the article has five sections. In Sect. 2, preliminaries are given including background on INTERPOL's secure communication linkage (I-24/7), MIND/FIND, and the Schengen Information System. The latter is an imperfect alternative to MIND/FIND for European Union (EU) countries, because this information system does not have global database coverage. The theoretical model is presented in Sect. 3. Sect. 4 describes the data and the 
empirical methodology, followed by the reporting of the empirical results and discussion of policy recommendations in Sect. 5. Concluding remarks are contained in Sect. 6.

\section{Preliminaries: On INTERPOL}

Established in 1923, INTERPOL is an independent international organization that fosters global cooperation in fighting international criminal activities. Currently, INTERPOL has 188 member countries, whose dues primarily fund its staff, offices, and operations. Member-assessed dues are based on an agreed-upon formula, which reflects, in part, members' income-based ability to pay. The remaining support for INTERPOL comes from voluntary contributions - in 2009, 19\% of its operations' budget of 58.7 million euros came from voluntary contributions from various organizations (INTERPOL 2010a).

INTERPOL links law enforcement agencies, the National Central Bureaus (NCBs), and the INTERPOL General Secretariat (IPGS) to curb transnational crime and terrorism, focusing on six priority criminal activities: corruption, drugs and organized crime, financial and hightechnology crime, fugitives, trafficking in humans, and transnational terrorism. Following 9/11, transnational terrorism was added as the sixth priority. Each member country's NCB, organizationally part of its national law enforcement apparatus and staffed with national law enforcement agents, interfaces with the General Secretariat, INTERPOL's seven regional offices (i.e., Argentina, Cameroon, Côte d'Ivoire, El Salvador, Kenya, Thailand, and Zimbabwe), and other member countries. Among its core functions, INTERPOL provides a secure global police communication network, criminal databases, police training and development, and dissemination of best practices. INTERPOL facilitates arrests by, among other means, issuing color-coded notices, and in particular Red as well as INTERPOL-UN Notices; the former are issued for suspected criminals and terrorists and the latter are specifically issued for al-Qaida and Taliban 
members. In addition, NCBs can issue diffusions that ask other member countries to arrest suspected criminals or terrorists. These arrests can be assisted by member countries and their law enforcement agents using INTERPOL's secure communication network, I-24/7, and other technology-based resources.

\section{$2.1 \mathrm{I}-24 / 7$}

I-24/7 is a restricted-access internet portal that provides secure global communication linkages to INTERPOL members and their law enforcement agents. This portal permits these agents to share information and to access INTERPOL databases and online resources at any time. I-24/7 is also used by INTERPOL and the NCBs to issue notices and diffusions, respectively. INTERPOL has compiled a variety of databases that are updated continually. Nominal data include known international criminals, terrorists, missing persons, and dead bodies. Other databases concern Stolen Motor Vehicles (SMV), Stolen and Lost Travel Documents (SLTD), DNA profiles, fingerprints, Stolen Works of Art, and Stolen Administrative Documents. SLTD is an invaluable tool for nabbing criminals and terrorists, who try to cross borders under assumed identities. Some terrorists involved in the September 11, 2001 (i.e., 9/11) hijackings and the March 11, 2004 (i.e., 3/11) Madrid commuter train bombings used stolen or false travel documents to enter the United States and Spain, respectively (US House of Representatives 2004; US Senate Judiciary Committee 2007).

\subsection{MIND/FIND}

At the end of 2005, INTERPOL offered member countries a new means of vigilance at ports of entry and border crossings. FIND and MIND provide a technical solution for law enforcement officials in the member countries to access INTERPOL databases remotely, either as a "fixed" 
access point that can be integrated into an already existing national database system, or as a "mobile" access point that permits autonomous queries on offline copies of INTERPOL databases (INTERPOL 2010b). In the case of MIND, stored copies of INTERPOL databases are updated every 48 hours or so. INTERPOL can track searches and "Hits," or search matches, to its databases when accessed by FIND. Whenever MIND is connected to I-24/7 for its periodic updates, its activity log alerts INTERPOL to all searches and Hits since the last update. By the end of 2009, 53 countries had deployed either FIND or MIND technologies. Some countries (i.e., Portugal, Romania, Russia, and the United States) adopted both technologies. The first MIND/FIND country was Switzerland, which deployed FIND on December 13, 2005. Other early adopters included the Bahamas, Belgium, France, Grenada, Lithuania, and Spain, which became MIND/FIND countries during 2006. There are a number of advantages that MIND/FIND offers countries. In mere seconds, a scanned passport can be checked against national and INTERPOL databases. Without MIND/FIND, searches are at the discretion of border officials, who must leave their duty station to run a check at the nearest I24/7 portal, which may either be at the border crossing station or at the country's NCB. Such searches would be motivated by suspicious behavior or appearance, which has a strong random component. At the I-24/7 portal, the border official would have to key in the passport number, which is not only time consuming, but also subject to error. With MIND/FIND, law enforcement authorities have the capacity to systematically check all passengers and immigrants; nothing needs to be left to discretion or chance. As new databases come into existence, MIND/FIND can allow ever-expanding access to INTERPOL and national databases. MIND/FIND also permits some cross-referencing of queries. If a passport from country $\mathrm{X}$ is flagged in country $\mathrm{Y}$, then country X will be alerted. The choice between MIND or FIND depends on the country's infrastructure - e.g., its computer hardware and Internet system. Since FIND allows online 
access, it has some small advantage over MIND owing to the freshness of the databases. More frequent updates to MIND would diminish this advantage.

Countries without MIND/FIND can still make arrests if persons raise suspicions and are in the national database, or if suspects are queried through the I-24/7 portal. Arrests may also result from a fugitive turning in him- or herself. In other instances, an arrest may follow alerts for authorities to be on the lookout for a specific individual. Hits found using I-24/7 are recorded by INTERPOL.

There are a number of expenses associated with deploying MIND/FIND; these costs vary by countries depending on their current infrastructure, staff training, and the number of installation sites (i.e., ports of entry and border crossings). The size of each site also makes a difference; a major international airport (e.g., Chicago’s O’Hare) will need more passport scanners, computer linkages, and software (INTERPOL 2010c) than a smaller international airport with fewer arriving passengers. Initial costs involve upgrades to the I-24/7 portal, whose expense may run to 100,000 euros or more. MIND/FIND also requires software that is customized to the countries' needs. A rough rule of thumb is that MIND/FIND costs about 1 million euros per site (INTERPOL 2010c). Countries with many international airports and seaports are likely to have larger MIND/FIND deployment cost. These costs involve computers, passport readers, video cameras, cameras to read vehicle license plates, power generators, training, and other hardware. Additional direct costs are associated with administrative, legal, and other budgetary line items. In Sect. 4 , the costs of MIND/FIND are approximated for a country by the aggregate number of its international airports and seaports.

Near the inception of MIND/FIND, external financial support was given to some Caribbean countries - e.g., Antigua and Barbuda, Barbados, Grenada, Jamaica, and St. Kitts and Nevis - to encourage their adoption of the technology. In 2008, external funding for 
MIND/FIND installation was also provided to Bosnia/Herzegovina, Croatia, Peru, the Philippines, Syria, and Ukraine. Russia received external support for both MIND and FIND in 2009 (data provided by the IPGS).

Launched in 2008, Operational Assistance, Services, and Infrastructure (OASIS) provides financial assistance to augment African police capacity and training (INTERPOL 2009). As part of OASIS, African countries can be subsidized to finance I-24/7 upgrades along with the expense of MIND/FIND deployments. OASIS supports MIND/FIND subsidization in order to shore up weakest-link entry points where criminals and terrorists can take advantage of unguarded transit or safe haven. Thus far, Ghana, Lesotho, and Senegal have had their MIND/FIND deployment externally funded through OASIS. Other African nations are currently taking part.

There is somewhat of a parallel European substitute for MIND/FIND, known as the Schengen Information System (SIS). SIS databases compile almost exclusively European information on fugitives, missing persons, stolen and lost travel documents, and stolen motor vehicles (European Parliament 2005; private communication with the IPGS). As such, SIS is not a perfect substitute for MIND/FIND. At international transit points, SIS member countries' officials can scan passports and send the information to the offices of the Supplementary Information Request at the National Entry (SIRENE) for checking instantaneously against databases. Information is transmitted across SISNET, a secure network like I-24/7. SIS countries are Austria, Belgium, the Czech Republic, Denmark, Estonia, Finland, France, Germany, Greece, Hungary, Italy, Latvia, Lithuania, Luxembourg, Malta, the Netherlands, Poland, Portugal, Slovakia, Slovenia, Spain, Sweden, Switzerland, and two associate countries Iceland and Norway. Because some substitution is possible between MIND/FIND and SIS, we shall check empirically whether SIS participation is negatively related to MIND/FIND adoption. An empirical finding of substitutability would imply the presence of an unexploited network 
externality, because the merging of INTERPOL and SIS databases would enhance the efficiency of both.

\section{Theoretical model}

MIND/FIND linkages provide country-specific, $x$, and global benefits, $Z$, by reducing the threat of crime and terrorism to member countries. Country-specific benefits arise from the apprehension of criminals and terrorists intending operations in that country, while global benefits stem from limiting the general threat to countries' interests posed by criminals and terrorists. The capture of criminal or terrorist groups' leaders or strategists can yield a mixture of country-specific and global benefits. Prime-target countries gain the most country-specific benefits. Because these countries have interests abroad, they gain from fewer criminal and terrorist operations on foreign soil. The world community also gains as property rights are protected from reduced crime abroad and political stability is enhanced from less terrorism. The protection of property rights bolsters international trade, which benefits the world community.

Each country, say $h$, chooses a private numeraire good, $y^{h}$, and its MIND/FIND activity, $q^{h}$, to maximize its strictly concave and increasing utility function,

$$
U^{h}=U^{h}\left(y^{h}, x^{h}, Z\right)
$$

subject to a budget or resource constraint,

$$
y^{h}+p^{h} q^{h}=I^{h}
$$

where the price of the private good is normalized to unity; country $h$ 's relative price of MIND/FIND is $p^{h}$; and country $h^{\prime}$ 's income is $I^{h}$. MIND/FIND country-specific and global public benefits are governed, respectively, by the following fixed-proportion production functions: 


$$
x^{h}=a^{h} q^{h}
$$

and

$$
z^{h}=b q^{h}
$$

where $a^{h}$ and $b$ are positive constants indicating the productivity of MIND/FIND in yielding the country-specific and global public benefit, respectively. That is, each unit of $h$ 's MIND/FIND activity yields $a^{h}$ units of $x^{h}$ and $b$ units of $z^{h}$. The latter is $h$ 's provision of the global public good from using MIND/FIND. The level of MIND/FIND participation is a choice variable because a country can decide the number of ports of entry and transit points to equip with MIND/FIND. The overall level of MIND/FIND-produced global public benefit is

$$
Z=Z^{h}+\tilde{Z}^{h}
$$

for which $\tilde{Z}^{h}=\sum_{i \neq h}^{H} z^{i}$ denotes the spillovers of these benefits from other MIND/FIND countries. In total, $H$ countries deploy MIND/FIND technologies.

By substituting (3)-(5) into the utility function, country $h$ confronts the following optimization problem:

$$
\underset{y^{h}, q^{h}}{\operatorname{maximize}}\left\{U^{h}\left(y^{h}, a^{h} q^{h}, b q^{h}+b \sum_{i \neq h}^{H} q^{i}\right) \mid y^{h}+p^{h} q^{h}=I^{h}\right\} \text {. }
$$

The first-order conditions (FOCs), associated with (6), can be expressed as

$$
a^{h} M R S_{x y}^{h}+b M R S_{z y}^{h}=p^{h}
$$

for MIND/FIND countries, and as

$$
a^{h} M R S_{x y}^{i}+b M R S_{z y}^{i}<p^{i}
$$

for non-MIND/FIND countries. In (7)-(8), MRS denotes the marginal rate of substitution - e.g., $M R S_{x y}^{h}=\frac{\partial U^{h}}{\partial x^{h}} / \frac{\partial U^{h}}{\partial y^{h}}$. Eq. (7) indicates that a MIND/FIND country equates its sum of country- 
specific and global public benefits, derived from its own deployment of MIND/FIND, to its MIND/FIND marginal costs. Countries may face different $p^{h}$ s depending on its existing infrastructure at entry points - i.e., INTERPOL countries may face larger or smaller marginal costs depending on their I-24/7 portals prior to adopting MIND/FIND. If, however, the derived MIND/FIND benefits are less than the associated marginal costs, then the country will not install the technology - see (8). Countries receiving sufficient marginal benefits from MIND/FIND will adopt the technology. This is more likely when country-specific marginal benefits are large; the country-derived global public benefits are large; or the marginal costs are small. A country that anticipates more criminals and/or terrorists to transit its borders will be more apt to install MIND/FIND. This is also true of countries that protect property rights and personal freedoms, as is the case of liberal democracies.

For connected countries, their demand for MIND/FIND is

$$
q^{h}=q^{h}\left(p^{h}, I^{h}, \tilde{Q}^{h}, a^{h}, b\right)
$$

where $\tilde{Q}^{h}=\sum_{i \neq h}^{H} q^{i}$. With income-normal goods, a rise in $p^{h}$ will reduce or inhibit MIND/FIND participation, while higher income will promote participation (Cornes and Sandler 1996). More MIND/FIND linkages by other countries (i.e., an increase in $\tilde{Q}^{h}$ ) may reduce participation by country $h$, given our summation aggregator and its implicit assumption of substitutability. However, this may be offset if the country-specific and global public benefits are complementary (Cornes and Sandler 1984). Increases in the country-specific and global productivity constants will augment the demand for MIND/FIND. International arrivals, democratic freedoms, and respect for laws will enhance the marginal benefits derived from MIND/FIND-provided security.

The FOCs in (7)-(8) are Pareto suboptimal because connected countries do not account for the benefits that their deployment of MIND/FIND confers on all other countries. The Pareto- 
optimal FOCs satisfies

$$
a^{h} M R S_{x y}^{h}+\sum_{i=1}^{N} b M R S_{z y}^{i}=p^{h}
$$

for every connected country, $h$, where global public benefits in (10) are sum over all $N$ (connected and unconnected) countries. Suboptimality, stemming from the absence of $\sum_{i \neq h}^{N} b M R S_{z y}^{i}$ in (7), provides a motive for INTERPOL, some international organization, or member countries (e.g., Germany in the OASIS project) to subsidize other countries' MIND/FIND connections.

Other public good aggregators can be introduced that limit the degree of substitutability for MIND/FIND among countries. For example, a weakest-link aggregator,

$$
Z=\min \left\{z^{1}, z^{2}, \ldots, z^{H}\right\}
$$

can replace the summation aggregator in (5). In (5'), the smallest or poorest MIND/FIND connection determines the total global public benefit achieved. Even if $Z=0$, countries may still join MIND/FIND owing to country-specific marginal benefits. In a weakest-link setting, there is an even stronger rationale for subsidizing other countries' MIND/FIND connections (Vicary and Sandler 2002).

\section{Empirical methodology and data}

\subsection{Methodology}

In the context of the model developed in Sect. 3, a country will adopt MIND/FIND if its utility from joining exceeds that from not joining. Since utility levels are not directly observable, we analyze the choice of an INTERPOL member deciding whether or not to adopt MIND/FIND 
using a binary choice model. Specifically, we denote $h$ 's maximal perceived net gain from adopting MIND/FIND as $U^{* h}$. The solution to Eq. (6) suggests that $U^{* h}$ will depend on the nation's income $\left(I^{h}\right)$, the relative price of MIND/FIND $\left(p^{h}\right)$, and the private member-specific benefits obtained from joining $\left(x^{h}\right)$. Because country $h$ receives MIND/FIND's global public benefit spillovers regardless of its adoption decision, these spillovers do not affect $U^{* h}$. As such, we can write $U^{* h}$ as

$$
U^{* h}=w^{h} \beta+\varepsilon^{h},
$$

where $w^{h}$ is the $1 \times K$ vector of explanatory variables, each denoted by $w_{k}^{h} ; \beta$ is a $K \times 1$ vector of parameters, each denoted by $\beta_{k}$; and $\varepsilon^{h}$ is a random disturbance, independent of $w^{h}$. In all of our estimations, the first regressor is always an intercept.

The value of $U^{*}$ is unobservable; we observe only the outcome of the decision of whether or not to adopt MIND/FIND. We, thus, let the binary choice of whether or not country $h$ adopts MIND/FIND to be represented by:

$$
u^{h}=\left\{\begin{array}{l}
1 \text { if } U^{* h} \geq 0 \\
0 \text { if } U^{* h}<0
\end{array}\right.
$$

The values of $\varepsilon^{h}$ can be drawn from a normal, logistic, or asymmetric extreme value (AEV) distribution. The distribution of $u^{h}$ given $w^{h}$ can be readily derived as:

$$
P\left(u^{h}=1 \mid w^{h}\right)=\Phi\left(w^{h} \beta\right),
$$

where $\Phi(\bullet)$ represents the appropriate cumulative normal, logistic, or AEV distribution and the estimated model is properly referred to as a probit, logit, or extreme value model, respectively. As such, the marginal influence of any variable $w_{k}^{h}$ on the probability that country $h$ adopts MIND/FIND is $\Phi^{\prime}\left(w^{h} \beta\right) \beta_{k}$. Since the value $\Phi^{\prime}$ changes with $w^{h} \beta$, we always report the marginal effect of any variable evaluated at the mean value of $w^{h} \beta$. 


\subsection{Data}

The dataset contains 195 countries, which includes the 188 INTERPOL member countries and their regional bureaus. The identification of the $53 \mathrm{MIND} / \mathrm{FIND}$ countries and their dates of adoption came from the IPGS, which also provided data on member countries' assessed membership contributions (CONTRIB) for 2005-2010 by year. For CONTRIB, an annual average of membership payments for 2005 and 2006 are used in the empirical tests for the MIND/FIND adoption decision. In addition, the IPGS supplied data on arrests made during 2005-2009 based on INTERPOL red notices or NCB-initiated diffusions. Although we experimented with several measures of arrests, we favor the number of arrests for a nation in the year prior to adopting MIND/FIND as a determinant of this decision. If a nation did not implement MIND/FIND, its INTERPOL-related arrests are then averaged for 2005-2009. The IPGS also supplied data on the number of searches and Hits during 2009 from the Nominal, SMV, and SLTD data banks. Data on searches and Hits for prior years are not maintained by INTERPOL. Additionally, the IPGS identified member countries that received external funding to implement MIND/FIND - e.g., through OASIS. Schengen countries were also identified by the IPGS. In our empirical analysis, SCHENGEN is a dummy variable with 1 assigned to member countries and 0 to nonmember countries.

We apply two different measures of political freedom in the estimates of the adoption decision. The first corresponds to political rights and civil liberties indices for 2007 from Freedom House (2010). Each index ranges from 1 to 7 with 1 indicating the greatest degree of rights and/or liberties. An overall index running from 2 to 14 is calculated by summing these two indices. If the sum is less than or equal to 5, indicating a free country, we set the dummy variable F. HOUSE equal to one; otherwise, we set the dummy variable equal to zero. For an 
alternative measure of democracy or freedom, we use the POLITY measure of Marshall and Jaggers (2009). For democracies, POLITY assigns a subjective index between 0 and 10 with larger values reflecting greater adherence to greater democratic principles. These scores increase when the country's institutions foster political participation; there are procedural restraints on executive power; and civil liberties are protected. For autocracies, POLITY assigns a subjective index between 0 and -10 , with smaller (more negative) values reflecting greater autocratic rule. Autocracy imposes constraints on political participation, has few curbs on executive power, and limits civil liberties significantly. The two indices are combined into a single index for each country for 2007 that ranges from -10 to 10 . For our estimations, we use a dummy variable equal to zero if the POLITY score is less than 7 and equal to unity otherwise. Countries with POLITY scores larger than or equal to 7 manifest significant democratic principles.

In addition, we employ two further measures of governance that prove useful when we instrument searches or Hits. The rule of law indicates “...perceptions of the extent to which agents have confidence in and abide by the rules of society, and in particular the quality of contract enforcement, property rights, the police, and the courts, as well as the likelihood of crime and violence" (Kaufman et al. 2008:7). This index (LAW) varies continuously between -2.5 and 2.5, in which larger values indicate closer observance of the law. Another governance measure is the control of corruption (CORRUPT) which measures the perception of the use of public power for private (illegitimate) gain (Kaufmann 2008:7). As for the rule of law, this corruption index varies between -2.5 and 2.5 , with larger values indicating less corruption.

We enter four socio-economic variables for the 195 sample countries. Gross domestic product per capita (GDP/POP) for 2007 in thousands of year 2000 US dollars is drawn from World Bank (2010). Missing values are filled in from data reported by the International Monetary Fund's (2010) International Financial Statistics. Population (POP) for 2007 is 
collected from World Bank (2010). Ethnic fractionalization (FRACTION) is taken from Alesina et al. (2003), who report a single value for each country. Ethnic fractionalization denotes the likelihood that two randomly chosen individuals from a country's population belong to two different groups based on racial, linguistic, and social considerations. The index varies between 0 and 1 , with higher values indicating greater ethnic diversity. The number of tourist arrivals (ARRIVALS) for each country during 2009 comes from NationMaster.com (2010) and serves as a proxy for the volume of people to be scrutinized at border crossings.

Finally, we seek a cost proxy for the implementation of MIND/FIND based on the number of international airports and seaports in a country. International airport data are collected using Europa World Plus (Europa) (2010), an online database that includes The Europa World Year Book and The Europa Regional Surveys of the World. Europa provides data on the principal international airports for most countries. Some entries in Europa are listed as "major" or "important" airports. If we found flights from these major airports to another country, we then included these airports in the data as an international airport. To find international flights, we consulted local airport websites (e.g., the four major airports in the Czech Republic each has a website listing international flights) and airline websites (e.g., Air-Zim in Zimbabwe and Air Moldova in Moldova). Europa failed to supply information on international airports for Australia, Canada, China, France, Italy, Russia, Spain, the United Kingdom, and the United States. The data for France are acquired from the Strategic Planning Directorate at INTERPOL. For the eight other countries, we obtain the number of international airports from Chambers (2005). Data on international airports are also collected from The Penguin Factfinder (Crystal 2005). The latter is not as complete; hence, we use Europa (2010) augmented by Chambers (2005). We also compile a list of international seaports from Europa (2010). Unfortunately, port data are missing in this source for Australia, Brazil, Germany, Iran, Italy, Malta, the Marshall 
Islands, Mexico, the Netherlands, Norway, Spain, Suriname, Turkey, the United Kingdom, the United States, and Uruguay. To address this problem, two additional lists of seaports are assembled from Chambers (2005) and the Central Intelligence Agency (2010), respectively. The data for some countries include ports in territories (e.g., Christmas Island and the Cocos Islands for Australia, New Caledonia for France, and the Cook Islands for New Zealand) and special administrative regions (e.g., Hong Kong and Macau for China). In our reported run, the PORTS variable includes the sum of Europa airports and seaports, with missing values filled in from Chambers (2005). Other unreported runs involve only airports or seaports. We also use the maximum values for each country's airports or seaports from the various data sources. The various measures of PORTS do not alter the findings reported in Sect. 5.

\section{Empirical results}

Table 1 reports the results of those variables that generally were statistically significant with estimated coefficients that were quite robust to alternative specifications and estimation methods. The top half of the table shows the estimated values of $\beta_{k}$ with the sample $t$-statistic in parentheses for the null hypothesis that $\beta_{k}=0$, based on each of the three alternative estimation methods (i.e., probit, logit, and extreme value). As anticipated, the natural logarithm of real per capita GDP (LGDP/POP) and country size (as measured by the logarithm of population, $L P O P$ ) always have a significant positive influence on MIND/FIND membership. For example, in the first probit formulation, $\beta_{2}$ (the coefficient for $L G D P / P O P$ ) is 0.338 and the $t$-statistic of 4.893 is significant at any conventional level. For the typical country, the marginal influence of $L G D P / P O P$ on the probability of adopting MIND/FIND is over 10 percentage points - see the bottom half of Table 1. These values are relatively insensitive to the inclusion of POLITY or the Freedom House measures of civil and political liberties. The estimates also are robust to 
alternative distributional assumptions concerning $\varepsilon^{h}$.

[Table 1 near here]

Country size (as measured by $L P O P$ ) also matters because it is always significant at the 0.025 level and its marginal effect is estimated to be at least 3.5 percentage points. Although this might seem like a small number, the range in $L P O P$ is substantial for the sample countries, which include not only small island nations, but also the most populous countries in the world, India and China. The most important explanatory variable entails the alternative measures of democractic and civil liberties. Both Freedom House and POLITY measures are always significant at any conventional level, with the marginal effects of increases in Freedom House and POLITY scores never less than 22.6 and 21.9 percentage points, respectively. Clearly, large countries with high levels of per capita income and democratic liberties are more likely than other countries to join MIND/FIND.

Comparing all 12 models, the probit estimation using the Freedom House measure of civil and political liberties has the best overall fit on the basis of pseudo $R^{2}$, Akaike information criterion (AIC), or Bayesian information criterion (BIC). However, a small caveat is in order since Aruba, the Cayman Islands, and Hong Kong do not have reported Freedom House and POLITY measures, so that this country/territory/region is not included in estimations containing one of these measures of democratic or civil liberties.

[Table 2 near here]

In order to gain a better understanding of the effect of income on MIND/FIND membership, we split the sample countries into two income categories. We use the World Bank's (2010) classification scheme, so that the 110 countries with per capita income levels below $\$ 3945$ are in the low to low-middle income group, and the other 85 countries are in the upper-middle to high income group. In comparing Tables 1 and 2, we see that dividing the 
sample generally reduces the statistical significance of the explanatory variables. This result is not especially surprising because each logit regression reported in Table 2 has about half the number of observations than the corresponding regression in Table 1. The important point to note is that the marginal effects of income are quite disparate for the two income groups. For the upper income countries, $L G D P / P O P$ is never significant and its marginal effect is always estimated to be about zero. In contrast, for the lower income countries, the marginal influence of $L G D P / P O P$ on the probability of MIND/FIND adoption is more than twice that shown in Table

1. There appears to be threshold behavior since increases in living standards greatly raise the likelihood that a relatively low-income country will adopt MIND/FIND. However, once per capita income surpasses a threshold value of $\$ 3945$, further increases in that variable have no effect on MIND/FIND adoption.

\section{[Table 3 near here]}

We are surprised that various cost measures do not influence MIND/FIND adoption. As reported in Table 3, PORTS and LCONTRIB/POP are not statistically significant when included as additional explanatory variables. One possible explanation is that, while countries with multiple entry points face high MIND/FIND installation costs, they also have much to gain from MIND/FIND adoption since they entertain relatively large numbers of tourist and business travelers. Yet, this argument is weakened by the fact that we never found ARRIVALS, per capita arrivals, or LARRIVALS (i.e., logarithm of arrivals) to be significant. Only the latter is reported in Table 3. It might be argued that nations with ethnic fractionalization (FRACTION) and/or large numbers of pre-installation ARRESTS might find it advantageous to join MIND/FIND. Similarly, it could be argued that nations utilizing SCHENGEN already have a tracking system that can substitute for MIND/FIND. Nevertheless, these variables (and transformations using logs and dividing by population) are not significant. For SCHENGEN, the sign is negative as 
anticipated, but not significant. These results are invariant to the distributional assumption concerning the error process and, for brevity, only the logit results are reported in Table 3 .

\subsection{Measuring anticipated benefits of MIND/FIND}

All INTERPOL members can access the Nominal, SLTD, and SMV databases. The principal advantages of MIND/FIND are that any information flows are virtually instantaneous and that the associated labor costs are minimal. Such access is important for law enforcement and immigration officials needing quickly to process large numbers of people and/or to request information. The model developed in Sect. 3 indicates that these perceived country-specific benefits of MIND/FIND (i.e., $x^{h}=a^{h} q^{h}$ ) should be a key determinant of actual MIND/FIND membership. Countries anticipating large benefits from MIND/FIND are more likely to implement the system. The problem in testing this implication of the model is that we have no direct ex ante measure of the perceived benefit of adopting MIND/FIND. Although INTERPOL did provide us with Nominal, SLTD, and SMV searches, we cannot use the actual number of searches directly as an explanatory variable because this measure is endogenous: MIND/FIND adopters are likely to have more searches than non-adopters because the access costs are relatively lower for the adopters.

In order to utilize searches as an explanatory variable, we need to find one or more suitable instruments. We favor instrumenting searches rather than Hits because searches better reflect the desire of countries to find criminals and terrorists. Hits suggest a pre-knowledge of the need for MIND/FIND that countries do not possess ex ante. It turns out that the various measures of governance (F. HOUSE, LAW, and CORRUPT) should be exogenous to the adoption of MIND/FIND, yet correlated with the adoption of MIND/FIND. Of course, when F. HOUSE and governance measures are used in the first-stage regression, it may or may not be 
desirable to include them as explanatory variables in the second stage (see Tables 1-3).

Moreover, since all instrumental variables' estimation is problematic in a probit framework, we also present results from a quasi-maximum likelihood estimation using ordinary least squares (OLS) with F. HOUSE, LAW, and CORRUPT as instruments. We report only the empirical results for Nominal searches, because civil and political liberty measures are found to be very weak instruments for SLTD and SMV searches.

[Table 4 near here]

The first-stage regression for the log of per capita Nominal searches $(L S R C H / P O P)$ is reported in the second column of Table 4. We note that the coefficients of F. HOUSE, LAW, and CORRUPT all have $t$-statistics that are greater than 2.0 in absolute value. The F-statistic for the exclusion of all three variables is 3.75 (with a prob-value of 0.011 ) and the F-statistic for the exclusion of LAW and CORRUPT is 3.16 (with a prob-value of 0.042). For the second-stage probit regression, we include $L G D P / P O P, L P O P, L S R C H / P O P$, and the residuals (RESIDS) from the first-stage regression. When we exclude F. HOUSE from the second-stage regression in the third column of Table 4, LSRCH/POP is significant at any conventional level and its marginal effect on the decision to adopt MIND/FIND is about ten percentage points. We also note that the residuals (RESIDS) from the first-stage regression are highly significant, indicating that $L S R C H / P O P$ is properly viewed as an endogenous variable. When we also include $F$. HOUSE in the second-stage regression, its $t$-statistic is only 1.163. Nevertheless, the marginal effect of $L S R C H / P O P$ on the probability of joining MIND/FIND remains at about ten percentage points. The quasi-maximum likelihood estimation (i.e., a linear model using F. HOUSE, LAW, and CORRUPT in the first-stage regression) indicates that the marginal effect of $L S R C H / P O P$ is about 14 percentage points, and falls to about nine percentage points when the insignificant $F$. HOUSE variable is present in the equation - see the last column of Table 4. 


\subsection{Outlier detection}

Perhaps even more interesting than the determinants of MIND/FIND adoption is the issue of countries that appear to be outliers in the sense that they share similar values for the key determinants of the adopter countries; however, these outlier countries do not adopt MIND/FIND. Outliers may also involve countries that adopt MIND/FIND even though their income per capita, population, and freedom measures would predict otherwise, based on our statistical analysis. We use the best-fitting model from Table 1 (i.e., the probit model with $F$. HOUSE) and the best-fitting instrument variable (IV) model from Table 4 (i.e., the probit IV model without F. HOUSE) to calculate the predicted probabilities that member countries adopt MIND/FIND. Of course, the realized probabilities are either zero or unity. The difference between the predicted and actual value indicates the extent to which a country chooses differently than similarly circumstanced countries.

The left-hand side of Table 5 shows the 15 countries with the largest positive and the largest negative discrepancies for the probit model without instrumenting Nominal searches. For example, the predicted probabilities that Germany, Australia, and Sweden use MIND/FIND are 0.734, 0.667 and 0.647 , respectively. Nevertheless, these countries do not adopt MIND/FIND despite large anticipated net gains from adoption, indicated in the third column of Table 5 based on Eq. (11). Germany and Sweden are both Schengen countries; hence, they may view SIS as an adequate substitute. Other SIS non-adopting countries among the predicted adopters are Denmark, Finland, Greece, Luxembourg, and Hungary. Hence, almost half of the non-adopters are Schengen users. The point is that in the top left-hand side of Table 5 are the non-adopters that have the highest predicted adoption probabilities $(P)$. In contrast, Bosnia/Herzegovina, the Syrian Arab Republic, and Guatemala are the least likely users of MIND/FIND, who 
nevertheless adopted that technology. Of the 15 least likely adopters, 11 were externally financed - the four exceptions are Algeria, Cuba, Guatemala, and Turkey. Thus, outlier adopters are primarily explained by external funding, which is an effective means of shoring up potential weakest-link countries where criminals and terrorists may seek to pass undetected. The righthand side of Table 5 reports the outlier results of the instrumental variable estimation. Among the non-adopters, eight are Schengen countries in the top right-hand side of Table 5, indicating again that Schengen is viewed by some likely adopters as a substitute to MIND/FIND. In the bottom right-hand side of Table 5, 13 of the 15 unlikely adopters had their MIND/FIND installations externally funded - the two exceptions are Lithuania and Guatemala. Thus, external funding is an effective means for inducing unlikely adopters to install MIND/FIND. Although the countries on the two sides of Table 5 are quite similar, there are some discrepancies. Some countries (e.g., Argentina, Uruguay, and Estonia) have many Nominal searches but have not implemented MIND/FIND and others (e.g., Montenegro, Lithuania, and Senegal) have few searches but are connected.

[Table 5 near here]

Our analysis of outliers has interesting policy conclusions. First, the presence of a parallel Schengen system serving EU and some associated countries is an impediment to the expansion of MIND/FIND and limits the full exploitation of network externalities that MIND/FIND offers. As long as Schengen provides more limited data access (i.e., European databases are generally associated with Schengen), it is not a perfect substitute and, thus, limits the achieved network externalities. Second, external financing of likely non-adopters (according to our statistical model) is an effective means for achieving greater implementation. Third, when the relatively small cost of MIND/FIND adoption is weighed against the huge benefits from capturing criminals and terrorists at border crossings (Sandler et al. 2011), any concerted effort 
to subsidize MIND/FIND adoption appears worthwhile. Finding institutionalized means for financing such subsidies would be desirable. Fourth, from a normative perspective, our analysis identifies the countries that should be subsidized, thereby helping ensure that funds are directed to where they can do the most good.

\section{Concluding remarks}

MIND/FIND represents an important crime-fighting technology in the presence of important cross-border network externalities. MIND/FIND initialization is inexpensive and has been shown to offer large returns from INTERPOL's terrorist-fighting collective action (arrests) (Sandler et al. 2011). Unfortunately, the MIND/FIND system is underutilized insofar as most INTERPOL members have not adopted MIND/FIND and some adopters institute a relatively small number of searches. We find that adopters of the MIND/FIND technology tend to be highincome liberal democracies with large populations. There are, however, some important exceptions; in particular, a number of Western European nations are not connected to MIND/FIND. Our outlier analysis suggests that is due, in part, to the presence of the Schengen Information System. Nevertheless, there are SIS users that have adopted MIND/FIND. Moreover, there are countries, not predicted to use MIND/FIND (e.g., Bosnia/Herzegovina, Syria, Guatemala, and the Russian Federation), which have adopted the technology. These unexpected adopters are by and large externally financed, which strongly suggests that subsidies have gone to where they did the most good. Interestingly, costs (as proxied by the number of entry points) played little role in the adoption calculus. Moreover, once a per-capita income threshold of 3945 US dollars is reached, the marginal effects of income on adoption lose explanatory power. 


\section{Acknowledgement}

This research was funded, in part, by the US Department of Homeland Security (DHS) through the Center for Risk and Economic Analysis of Terrorism Events (CREATE) at the University of Southern California, grant number 2010-ST-061-RE0001. Any opinions, findings, and conclusions or recommendations are solely those of the authors and do not necessarily reflect the views of DHS, or CREATE. 


\section{References}

Alesina, A., Devleeschauwer, A., Easterly, W., Kurlat, S., \& Wacziarg, R. (2003).

Fractionalization. Journal of Economic Growth, 82(2), 155-194.

Central Intelligence Agency. (2010). The world factbook.

https://www.cia.gov/library/publications/the-world-factbook. Accessed 9/15/2010.

Chambers Book of Facts. (2005). Chambers book of facts. Edinburgh: Chambers Harrap Publishers Ltd.

Cornes, R., \& Sandler, T. (1984). Easy riders, joint production, and public goods. Economic Journal, 94(3), 580-598.

Cornes, R. \& Sandler, T. (1996). The theory of externalities, public goods and club goods. Cambridge: Cambridge University Press.

Crystal, D. (ed). (2005). The Penguin factfinder. London: Penguin Books.

Europa World Plus. (2010). Airports. http://www.europaworld.com. Accessed 9/15/2010.

European Parliament. (2005). Schengen Information System (SIS).

http://www.europarl.europa.eu/comparl/libe/elsj/zoom_in/25 en.htm. Accessed: 2/28/2011.

Freedom House. (2010). Freedom in the world country ratings, 1972-2009.

http://www.freedomhouse.org. Accessed 12/29/2010.

International Monetary Fund. (2010). International financial statistics. CD ROM. Washington DC: International Monetary Fund.

INTERPOL. (2009). OASIS Africa. Fact Sheet, COM/FS/2009-06/GI-06. Lyon: INTERPOL. INTERPOL. (2010a). INTERPOL annual report 2009. http://www.interpol.int/Public/ICPO/InterpolAtWork/iaw2009.pdf. Accessed: 12/12/2010. 
INTERPOL. (2010b). MIND/FIND providing law enforcement with instant worldwide access to Interpol databases. http://www.interpol.int/public/FindAndMind/Default.asp. Accessed $12 / 09 / 2010$

INTERPOL. (2010c). Assessment of components of costs involved in the expansion of INTERPOL services beyond the NCB. Private communication made up by MIND/FIND staff at the INTERPOL General Secretariat.

Kaufmann, D., Kraay, A., \& Mastruzzi, M. (2008). Governance matters VII: Aggregate and individual governance indicators, 1996-2008. World Bank Policy Research Working Paper, June 2009. Washington, DC: World Bank. http://www.govindicators.org/. Accessed: 6/20/2010.

Marshall, M. G., \& Jaggers, K. (2009). Polity IV dataset version 2007 and Dataset users' manual. Fairfax, VA: Center for Systemic Peace and Center for Global Policy, George Mason University. http://www.systemicpeace.org. Accessed 7/1/2009.

NationMaster.com. (2010). Tourist arrivals (most recent) by country. http://www.nationmaster.com/graph/eco tou_arr-economy-tourist-arrivals. Accessed 11/7/2010.

Sandler, T. (2005). Collective versus unilateral responses to terrorism. Public Choice, 124(1-2), $75-93$.

Sandler, T., Arce, D. G., \& Enders, W. (2011). An evaluation of INTERPOL cooperative-based counterterrorism linkages. Journal of Law and Economics, 54(1), Forthcoming.

Vicary, S., \& Sandler, T. (2002). Weakest-link public goods: Giving in-kind on transferring money. European Economic Review, 46(8), 1501-1520.

United States House of Representatives. (2004). Stolen passports: A terrorist's first class ticket. Hearing Before the Committee on International Relations, Serial No. 108-117, 
June 29. Washington, DC: House of Representatives.

United States Senate Judiciary Committee. (2007). Statement of Ronald K. Noble, Secretary General of INTERPOL before the Subcommittee on Terrorism, Technology, and Homeland Security. US Senate, May 2. Washington, DC: US Senate.

World Bank. (2010). World development indicators. http://www.worldbank.org. Accessed $11 / 7 / 2010$ 
Table 1 The basic regressions

\begin{tabular}{|c|c|c|c|c|c|c|c|c|c|}
\hline & \multicolumn{3}{|c|}{ Probit } & \multicolumn{3}{|c|}{ Logit } & \multicolumn{3}{|c|}{ Extreme value } \\
\hline Constant & $\begin{array}{r}-2.797 \\
(-3.744)\end{array}$ & $\begin{array}{r}-3.403 \\
(-4.209)\end{array}$ & $\begin{array}{r}-3.562 \\
(-4.339)\end{array}$ & $\begin{array}{r}-4.834 \\
(-3.685)\end{array}$ & $\begin{array}{r}-5.795 \\
(-4.139)\end{array}$ & $\begin{array}{r}-5.878 \\
(-4.209)\end{array}$ & $\begin{array}{r}-4.663 \\
(-4.257)\end{array}$ & $\begin{array}{r}-5.265 \\
(-4.727)\end{array}$ & $\begin{array}{r}-5.173 \\
(-4.767)\end{array}$ \\
\hline LGDP/POP & $\begin{array}{r}0.338 \\
(4.893)\end{array}$ & $\begin{array}{r}0.262 \\
(3.429)\end{array}$ & $\begin{array}{r}0.234 \\
(2.970)\end{array}$ & $\begin{array}{r}0.562 \\
(4.712)\end{array}$ & $\begin{array}{r}0.435 \\
(3.313)\end{array}$ & $\begin{array}{r}0.378 \\
(2.786)\end{array}$ & $\begin{array}{r}0.465 \\
(4.931)\end{array}$ & $\begin{array}{r}0.343 \\
(3.284)\end{array}$ & $\begin{array}{r}0.293 \\
(2.641)\end{array}$ \\
\hline$L P O P$ & $\begin{array}{r}0.114 \\
(2.484)\end{array}$ & $\begin{array}{r}0.126 \\
(2.640)\end{array}$ & $\begin{array}{r}0.141 \\
(2.893)\end{array}$ & $\begin{array}{r}0.201 \\
(2.535)\end{array}$ & $\begin{array}{r}0.216 \\
(2.658)\end{array}$ & $\begin{array}{r}0.232 \\
(2.827)\end{array}$ & $\begin{array}{r}0.185 \\
(2.841)\end{array}$ & $\begin{array}{r}0.185 \\
(2.886)\end{array}$ & $\begin{array}{r}0.188 \\
(2.989)\end{array}$ \\
\hline POLITY & & $\begin{array}{r}0.807 \\
(3.232)\end{array}$ & & & $\begin{array}{r}1.379 \\
(3.103)\end{array}$ & & & $\begin{array}{r}1.161 \\
(2.916)\end{array}$ & \\
\hline F. HOUSE & & & $\begin{array}{r}0.871 \\
(3.484)\end{array}$ & & & $\begin{array}{r}1.443 \\
(3.299)\end{array}$ & & & $\begin{array}{r}1.180 \\
(3.064)\end{array}$ \\
\hline & & & & MARGINA & EFFECT & & & & \\
\hline$L G D P / P O P$ & 0.106 & 0.079 & 0.071 & 0.102 & 0.075 & 0.066 & 0.094 & 0.065 & 0.056 \\
\hline$L P O P$ & 0.036 & 0.038 & 0.043 & 0.036 & 0.037 & 0.040 & 0.037 & 0.035 & 0.036 \\
\hline $\begin{array}{l}\text { POLITY } \\
\text { F. HOUSE }\end{array}$ & & 0.244 & 0.264 & & 0.238 & 0.252 & & 0.219 & 0.226 \\
\hline & & & & MEASUR & ES OF FIT & & & & \\
\hline Pseudo $R^{2}$ & 0.146 & 0.208 & 0.216 & 0.144 & 0.205 & 0.210 & 0.147 & 0.204 & 0.206 \\
\hline$A I C$ & 205.408 & 193.564 & 191.939 & 205.683 & 194.185 & 193.186 & 205.168 & 194.359 & 193.931 \\
\hline BIC & 215.227 & 206.594 & 204.969 & 215.502 & 207.215 & 206.216 & 214.987 & 207.389 & 206.961 \\
\hline
\end{tabular}

Each model was estimated using a probit, logit, and extreme value distribution. Entries in the top portion are the beta coefficients with the $t$-statistic in parentheses. Note that all coefficients for all models are significant at the $5 \%$ level. Entries in the middle portion of the table are the marginal effects of each variable. Goodness of fit measures are shown in the lower portion of the table. 
Table 2 The basic logit regressions by income classification

\begin{tabular}{|c|c|c|c|c|c|c|}
\hline \multirow[b]{2}{*}{ Constant } & \multicolumn{3}{|c|}{$\begin{array}{l}\text { Low to Low-Middle } \\
\text { Income Group }\end{array}$} & \multicolumn{3}{|c|}{$\begin{array}{l}\text { Upper-Middle to High } \\
\text { Income Group }\end{array}$} \\
\hline & -5.232 & -6.014 & -6.874 & -3.040 & -4.283 & -3.843 \\
\hline & $(-2.414)$ & $(-2.644)$ & $(-2.890)$ & $(-1.765)$ & $(-2.249)$ & $(-2.080)$ \\
\hline$L G D P / P O P$ & 1.117 & 0.949 & 0.797 & -0.016 & 0.013 & -0.011 \\
\hline & (2.895) & (2.325) & (1.983) & $(-0.059)$ & $(0.044)$ & $(-0.040)$ \\
\hline$L P O P$ & $\begin{array}{r}0.212 \\
(1.614)\end{array}$ & $\begin{array}{r}0.219 \\
(1.629)\end{array}$ & $\begin{array}{r}0.271 \\
(1.937)\end{array}$ & $\begin{array}{r}0.187 \\
(1.899)\end{array}$ & $\begin{array}{r}0.207 \\
(2.035)\end{array}$ & $\begin{array}{r}0.203 \\
(2.000)\end{array}$ \\
\hline POLITY & & $\begin{array}{r}1.386 \\
(2.258)\end{array}$ & & & $\begin{array}{r}1.111 \\
(1.709)\end{array}$ & \\
\hline F. HOUSE & & & $\begin{array}{r}1.919 \\
(2.977)\end{array}$ & & & $\begin{array}{r}0.769 \\
(1.323)\end{array}$ \\
\hline \multicolumn{7}{|c|}{ MARGINAL EFFECTS } \\
\hline$L G D P / P O P$ & 0.238 & 0.194 & 0.159 & -0.004 & 0.003 & -0.003 \\
\hline$\angle P O P$ & 0.045 & 0.045 & 0.054 & 0.047 & 0.049 & 0.049 \\
\hline $\begin{array}{l}\text { POLITY } \\
\text { F. HOUSE }\end{array}$ & & 0.284 & 0.383 & & 0.264 & 0.186 \\
\hline \multicolumn{7}{|c|}{ MEASURES OF FIT } \\
\hline Pseudo $R^{2}$ & 0.120 & 0.172 & 0.209 & 0.046 & 0.081 & 0.065 \\
\hline AIC & 87.878 & 84.099 & 80.172 & 116.852 & 113.724 & 115.114 \\
\hline BIC & 96.007 & 94.901 & 90.974 & 124.145 & 123.351 & 124.741 \\
\hline
\end{tabular}

Entries in the top portion are the beta coefficients with the $t$-statistic in parentheses. Entries in the middle portion of the table are the marginal effects of each variable. Goodness of fit measures are shown in the lower portion of the table. In accord with the World Bank (2010) classification scheme, the 110 countries in our sample with a per capita GDP level below \$3945 are in the Low to Low-Middle Income group. The other 85 countries are in the Upper-Middle to High Income group. 
Table 3 Additional explanatory variables: logit regressions

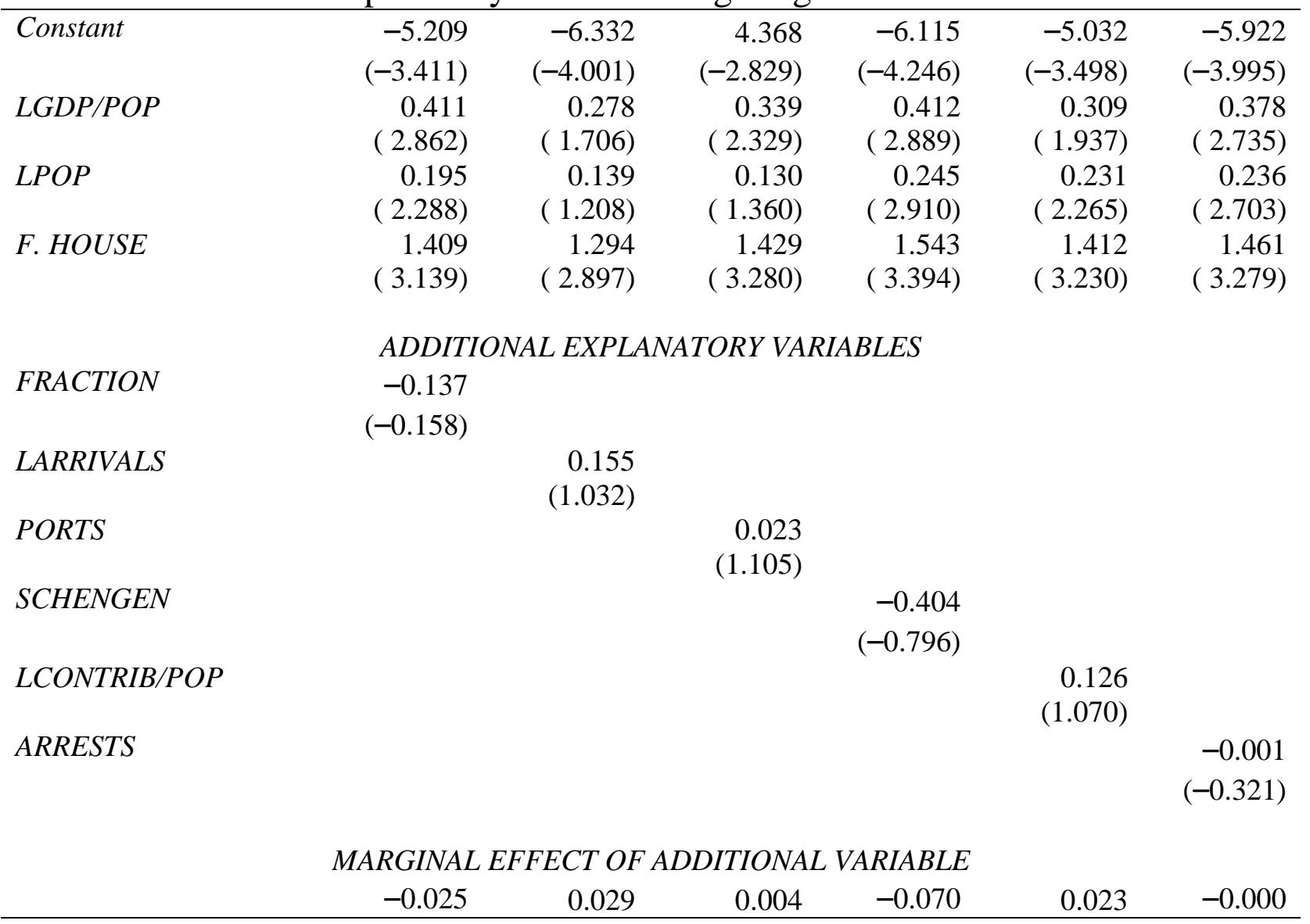

Entries in the top portion are the beta coefficients with the $t$-statistic in parentheses. Note that most of the coefficients appearing in the Basic Model are significant at the $5 \%$ level. Since there are missing values for each of the additional variables (except SCHENGEN), the goodness of fit measures are not reported because they are not comparable across equations. 
Table 4 The instrumental variable (IV) models

\begin{tabular}{|c|c|c|c|c|c|}
\hline & $\begin{array}{l}\text { First- } \\
\text { Stage }\end{array}$ & $\begin{array}{c}\text { Probit } \\
\text { IV Model }\end{array}$ & $\begin{array}{c}\text { Probit } \\
\text { IV Model }\end{array}$ & $\begin{array}{c}\text { Linear IV } \\
\text { Model }\end{array}$ & $\begin{array}{c}\text { Linear IV } \\
\text { Model }\end{array}$ \\
\hline \multirow[t]{2}{*}{ Constant } & -1.594 & -2.682 & -3.042 & -0.288 & -0.397 \\
\hline & $(-0.822)$ & $(-2.871)$ & $(-3.197)$ & $(-0.826)$ & $(-1.416)$ \\
\hline \multirow[t]{2}{*}{$L G D P / P O P$} & 0.696 & -0.157 & -0.043 & -0.034 & -0.006 \\
\hline & ( 2.798) & $(-0.925)$ & $(-0.241)$ & $(-0.627)$ & $(-0.129)$ \\
\hline \multirow[t]{2}{*}{$L P O P$} & -0.528 & 0.435 & 0.337 & 0.117 & 0.088 \\
\hline & $(-4.316)$ & ( 3.981$)$ & ( 2.541) & ( 3.540$)$ & ( 2.689) \\
\hline \multirow[t]{2}{*}{ F. HOUSE } & 1.375 & & 0.441 & & 0.145 \\
\hline & ( 2.055$)$ & & (1.163) & & ( 1.275$)$ \\
\hline \multirow[t]{2}{*}{ CORRUPT } & 2.186 & & & & \\
\hline & ( 2.512) & & & & \\
\hline \multirow[t]{2}{*}{$L A W$} & -2.160 & & & & \\
\hline & $(-2.222)$ & & & & \\
\hline \multirow[t]{2}{*}{ LSRCH/POP } & & 0.561 & 0.372 & 0.145 & 0.090 \\
\hline & & ( 3.438$)$ & (1.724) & ( 2.701$)$ & ( 1.621$)$ \\
\hline \multirow[t]{3}{*}{ RESIDS } & & -0.440 & -0.253 & & \\
\hline & & $(-2.660)$ & $(-1.162)$ & & \\
\hline & & \multicolumn{4}{|c|}{ MARGINAL EFFECTS } \\
\hline \multicolumn{2}{|l|}{$L G D P / P O P$} & -0.028 & -0.010 & -0.034 & \\
\hline \multicolumn{2}{|l|}{ LPOP } & 0.078 & 0.080 & 0.117 & \\
\hline \multicolumn{2}{|l|}{ F. HOUSE } & & 0.089 & & \\
\hline \multicolumn{2}{|l|}{ LSRCH/POP } & 0.101 & 0.105 & 0.145 & 0.090 \\
\hline
\end{tabular}

The various measures of goodness of fit are not reported because they are not comparable across the alternative distributions. 
Table 5 Predicted versus actual membership in MIND/FIND

\begin{tabular}{|c|c|c|c|c|c|}
\hline Country & $P$ & $w^{h} \beta$ & Country & $P$ & $w^{h} \beta$ \\
\hline & \multicolumn{2}{|c|}{ Probit Model } & & \multicolumn{2}{|c|}{ Probit IV Model } \\
\hline \multicolumn{6}{|c|}{ NON-ADOPTERS PREDICTED TO ADOPT MIND/FIND } \\
\hline Germany & 0.734 & 0.626 & Argentina & 0.858 & 1.071 \\
\hline Australia & 0.667 & 0.430 & Finland & 0.758 & 0.700 \\
\hline Sweden & 0.647 & 0.377 & Iceland & 0.725 & 0.598 \\
\hline Denmark & 0.620 & 0.307 & Uruguay & 0.696 & 0.512 \\
\hline Argentina & 0.614 & 0.291 & Germany & 0.671 & 0.442 \\
\hline Ireland & 0.607 & 0.272 & Estonia & 0.669 & 0.437 \\
\hline Finland & 0.607 & 0.271 & Sweden & 0.661 & 0.415 \\
\hline Israel & 0.597 & 0.245 & Denmark & 0.640 & 0.358 \\
\hline Greece & 0.588 & 0.224 & Australia & 0.556 & 0.142 \\
\hline India & 0.560 & 0.150 & New Zealand & 0.537 & 0.092 \\
\hline New Zealand & 0.553 & 0.134 & Ireland & 0.506 & 0.015 \\
\hline Luxembourg & 0.537 & 0.093 & Dom. Rep. & 0.499 & -0.002 \\
\hline Thailand & 0.526 & 0.065 & Colombia & 0.492 & -0.020 \\
\hline Nauru & 0.520 & 0.050 & Luxembourg & 0.492 & -0.021 \\
\hline Hungary & 0.500 & 0.001 & Netherlands & 0.471 & -0.072 \\
\hline
\end{tabular}

ADOPTERS PREDICTED NOT TO ADOPT MIND/FIND

\begin{tabular}{llllll} 
Turkey & 0.263 & -0.635 & Montenegro & 0.341 & -0.410 \\
St. Kitts/Nevis & 0.250 & -0.674 & Lithuania & 0.334 & -0.429 \\
Grenada & 0.241 & -0.703 & Senegal & 0.332 & -0.434 \\
St. Vincent/Gren. & 0.238 & -0.714 & Lesotho & 0.286 & -0.565 \\
Guyana & 0.220 & -0.771 & Bosnia/Herzegovina & 0.274 & -0.601 \\
Dominica & 0.219 & -0.776 & Philippines & 0.240 & -0.707 \\
Cuba & 0.213 & -0.796 & Barbados & 0.220 & -0.774 \\
Lesotho & 0.209 & -0.811 & Ghana & 0.204 & -0.826 \\
Algeria & 0.172 & -0.945 & Guatemala & 0.203 & -0.831 \\
Trinidad/Tobago & 0.153 & -1.024 & Trinidad/Tobago & 0.183 & -0.903 \\
Ukraine & 0.146 & -1.053 & Dominica & 0.140 & -1.081 \\
Russian Federation & 0.145 & -1.058 & Jamaica & 0.132 & -1.118 \\
Guatemala & 0.134 & -1.108 & Grenada & 0.117 & -1.188 \\
Syrian A.R. & 0.128 & -1.138 & Guyana & 0.113 & -1.211 \\
Bosnia/Herzegovina & 0.104 & -1.259 & Syrian A.R. & 0.047 & -1.674 \\
\hline P isthe predicted
\end{tabular}

$P$ is the predicted probability that a country implements MIND/FIND and $w^{h} \beta$ is the predicted net gain from joining MIND/FIND from Eq. (11). 